\title{
Review
}

\section{Human gut microbiota and healthy aging: Recent developments and future prospective}

\author{
Manish Kumar, Parizad Babaei, Boyang Ji and Jens Nielsen* \\ Department of Biology and Biological Engineering, Chalmers University of Technology, Gothenburg, Sweden
}

\begin{abstract}
The human gut microbiota alters with the aging process. In the first 2-3 years of life, the gut microbiota varies extensively in composition and metabolic functions. After this period, the gut microbiota demonstrates adult-like more stable and diverse microbial species. However, at old age, deterioration of physiological functions of the human body enforces the decrement in count of beneficial species (e.g. Bifidobacteria) in the gut microbiota, which promotes various gut-related diseases (e.g. inflammatory bowel disease). Use of plant-based diets and probiotics/prebiotics may elevate the abundance of beneficial species and prevent gut-related diseases. Still, the connections between diet, microbes, and host are only partially known. To this end, genome-scale metabolic modeling can help to explore these connections as well as to expand the understanding of the metabolic capability of each species in the gut microbiota. This systems biology approach can also predict metabolic variations in the gut microbiota during ageing, and hereby help to design more effective probiotics/prebiotics.
\end{abstract}

Keywords: Human gut microbiota, aging, diets, probiotics/prebiotics, genome-scale metabolic modeling

\section{Introduction}

Aging is defined as deterioration of physiological functions accompanied by the development of age [18]. Based on several studies a connection between the human gut microbiota and aging is becoming evident [5, 19-21]. A significant number of studies have elucidated that human health needs a beneficial gut microbiota for physical and mental development at every age [22] and alteration in physiological functions during the aging process can affect the composition and functions of species in the gut microbiota. A major negative consequence of aging is immunosenescence, which can be defined as a decline in the functionality of the immune system [23], which can cause a chronic low-grade inflammatory status in the gut. Immunosenescence can therefore cause unfavorable changes in the composition and structure of the gut microbiota in older people. Moreover, perturbation in the gut microbiota is associated with various metabolic and inflammatory disorders such

\footnotetext{
${ }^{*}$ Corresponding author: Jens Nielsen, Department of Biology and Biological Engineering, Chalmers University of Technology, SE-412 96 Gothenburg, Sweden. Tel: +46 031772 3804; Fax: +46031772 3801; E-mail: nielsenj@chalmers.se.
}

as obesity [24], inflammatory bowel disease [25, 26], irritable bowel syndrome [27, 28] type 1 and type 2 diabetes [29-32], atherosclerosis [33, 34], allergy [35], autism [36], and familial Mediterranean fever [37]. Altogether, deterioration in gut-related functions and development can affect the gut microbiota during aging [38].

Diet, which has been investigated in human subjects and model host [39-44], is a major modulator for the gut microbiota [45]. However, it is poorly known how diet influences composition and function of the gut microbiota and how diet-microbe, microbemicrobe, and microbe-host interact [20].

Here we review recent research developments in exploring the association between the gut microbiota and aging. We also highlight the contribution of diet and probiotics/prebiotics to maintain a beneficial gut microbiota, and thus contribute to healthy aging. In order to design a healthy diet and novel probiotics/prebiotics, this review includes information about effective approaches that can be employed to acquire better understanding of (i) metabolic capability of microbial species in the gut microbiota and (ii) interactions between diet, microbes and host in aging. 


\section{Variability in the gut microbiota during early life among healthy subjects}

Culture-independent techniques for microbiome examination have suggested that there is not a core set of species-level phylotypes for healthy or normal gut microbiota in humans at individual- and inter-individual-level [46]. The microbial community composition in the gut differs at inter-individual-level largely on the basis of region-specific diet, geography, health, host genetics, early microbial exposure and age [26, 30, 47-49] and these factors are also responsible for inducing variability in the gut microbiota over time at the individual-level [50]. It is believed that during birth, the infant gut contains no microbial community or at least very few species. Subsequently, the gut microbiota alters drastically during different stages such as colonization, development, and maturation within the first two years of life. Along with the factors described above, there are more factors such as mode of delivery (vaginal or cesarean), exposure to antibiotics, feeding type, hospital environment and use of prebiotic/probiotic, which play significant roles in the variability of microbial community at the early age of life (Fig. 1) [51]. Comparative studies on mode of delivery have demonstrated that colonization of microbes in the gut differs in vaginal and cesarean delivery, which impacts the development of the immune system in early age of infants [52-54]. These studies demonstrated that the gut microbiota in children delivered by cesarean section contains a lower abundance of Bifidobacteria, Bacteroides Staphylococcus, Corynebacterium, and Propionibacterium spp. and higher abundance of Lactobacillus, Prevotella, Sneathia spp., and Clostridium difficile compared to children delivered vaginally. High abundance of $C$. difficile represents can cause dysbiosis and increased risk for developing obesity $[22,55]$. Similarly, exposure to antibiotics in infancy directly alters the gut microbiota (Table 1), which enforces unusual weight gain in infants and contributes to autoimmune diseases such as inflam-

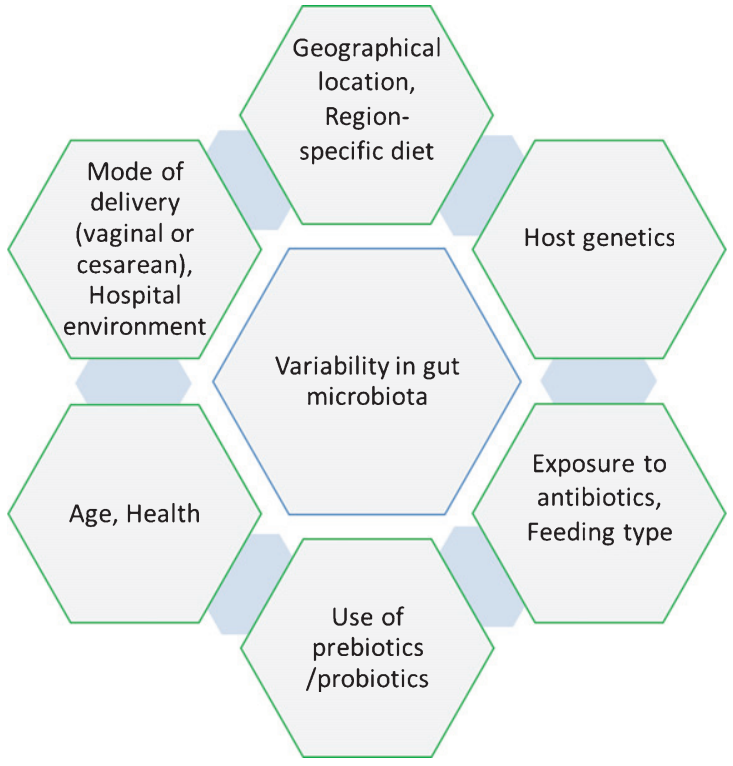

Fig. 1. Factors responsible for inducing the variability in the human gut microbiota.

matory bowel disease, asthma, allergies, arthritis and multiple sclerosis, but the mechanism behind this variation remains unclear [56-58]. Moreover, the type of feeding was also found as a critical factor for variability in the gut microbiota of infants [59]. Human breast milk contains a complex and dynamic composition influenced by gestational age, lactation period and mother's diet, which differs from general formula feeding in the concentration and composition of nutrients, especially for the presence of hormones, growth factors, immunoglobins and enzymes [60]. A study suggested that formula-fed infants contain higher abundance of Escherichia coli, C. difficile, Bacteroides, and Lactobacilli than breastfed infants (Table 1). Altogether, vaginal delivery and breast-feeding were suggested as being optimal for maintaining a healthy gut microbiota (higher abundance of Bifidobacteria and lower abundance of $C$. difficile and E. coli) [61].

Table 1

High-abundance bacteria in the human (infant) gut microbiota depending on modes of delivery and feeding

\begin{tabular}{llc}
\hline Factors & High-abundance bacteria & References \\
\hline Vaginal delivery & Bifidobacteria, Bacteroides Staphylococcus, & {$[55]$} \\
& $\quad$ Corynebacterium, and Propionibacterium spp. & \\
Cesarean delivery & Lactobacillus, Prevotella, Sneathia spp., and Clostridium difficile & {$[55]$} \\
Formula feeding & Escherichia coli, C. difficile, Bacteroides, and Lactobacilli & {$[61]$} \\
Breast feeding & Bifidobacteria & {$[61]$} \\
\hline
\end{tabular}




\section{What are the microbial signatures associated with healthy aging?}

Since the global population is aging towards a less active population, this is one of the major goals to prevent or delay age-related diseases and maintain reasonably good health $[62,63]$. To date, the association between the gut microbiota and aging is poorly understood. However, several studies have suggested that maintaining a balanced gut microbiota through having fiber/microbiotaaccessible-carbohydrates (MACs)-containing diets or taking the right pro/prebiotics may help in prevention and treatment of age-related pathophysiological conditions, which can promote longevity [64-68]. Maintaining a balanced gut microbiota is meant that gut microbiota would be shaped in a beneficial manner using intervention of fiber-rich diets for improving the healthspan through improving gut barrier function, reducing markers of oxidative stress and inflammation, and enhancing cognitive and motor performance [67]. Microbes start colonizing in the gut from the time of birth and reaches maturation within the first two years [51]. Moreover, it is believed that the gut microbiota shows a stable form throughout the adulthood, but it acclimates changes during the aging process (Fig. 2) [5, 69-71]. Recently, few attempts have been taken to understand the correlation between aging and the gut microbiota. Most studies have analyzed variation in the gut microbiota at different stages of host age [69, 72, 73], but there have also been studies on looking into the variability at the individual-level in older subjects $[74,75]$. Moreover, the impact of aging on the gut microbiota was found to be country-specific which is in turn influenced by specific diets and lifestyles [73, 76].

Studies on aging gut microbiota have revealed that the composition of microbiota in elders is considerably different from that of younger adults. To this end, specifically a very low abundance of phylum Firmicutes and an overall low diversity were detected in elderly subjects [77-81], and low diversity has been found to associate with increased health risks [82]. Another study has reported significantly higher abundance of Bacteroidetes, and lower abundance of Clostridium cluster IV in elders compared to younger subjects [83]. The effect of presence of pathogens and antibiotics treatment on composition of the gut microbiota has been also investigated in elderly subjects. Fecal microbiota of elderly subjects were examined with and without the treatment of antibiotics. The gut

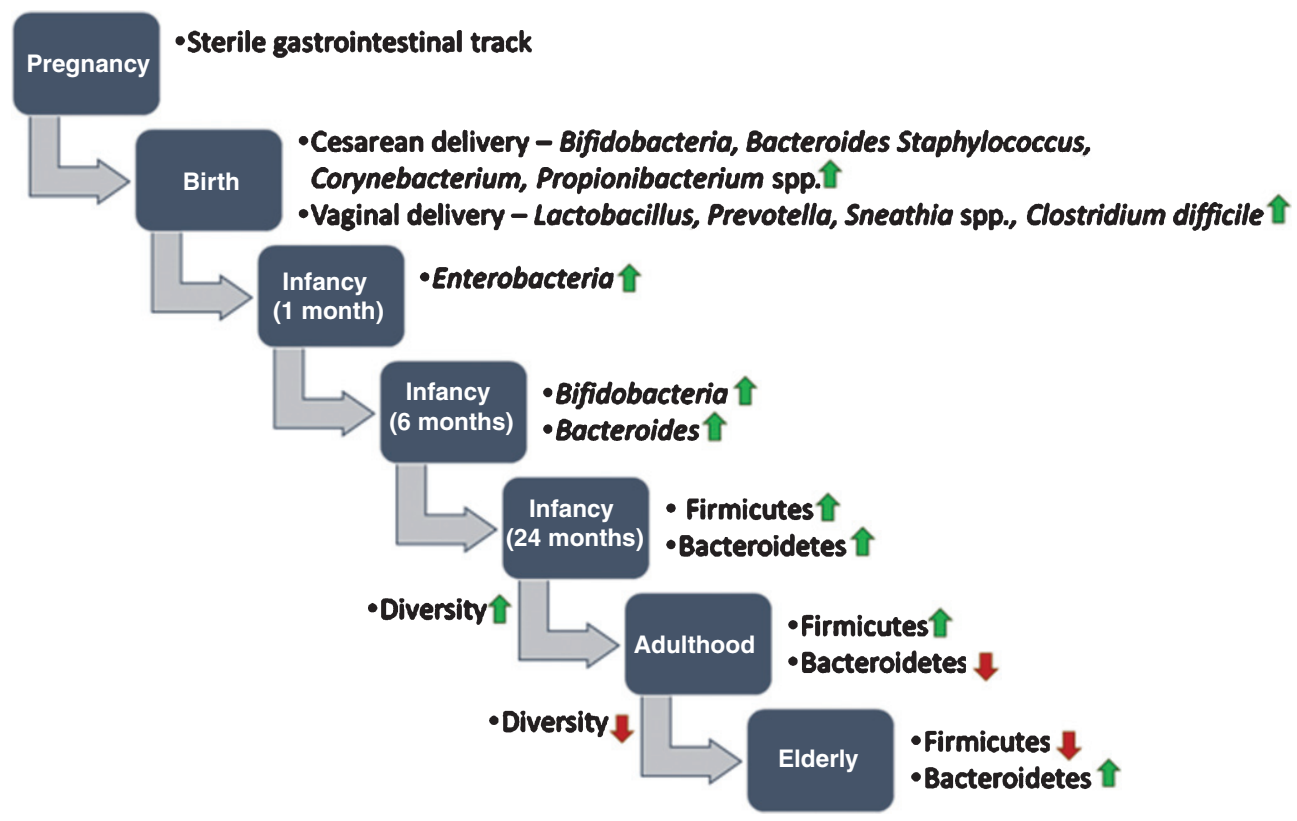

Fig. 2. Development of human gut microbiota from prenatal to elderly. It is believed that infants are born with a sterile gastrointestinal track. During birth, the infant gut is exposed to microbes from the mother's reproductive tract and environment and the gut microbiota starts colonizing. Up to the first two years of life, the composition of the gut microbiota often varies. After two years, when children are started to eat solid food (e.g. fibers and complex carbohydrates), the gut microbiota becomes more diverse and stable. In old age, the gut microbiota alters drastically and shows less diversity compared to younger age. 
Table 2

High- and low-abundance bacteria in the human (elderly) gut microbiota influenced by various factors

\begin{tabular}{lllc}
\hline Factors & High-abundance bacteria & Low-abundance bacteria & References \\
\hline Health & Bacteroidetes & Firmicutes, and Clostridium cluster IV & [77-81, 83] \\
Antibiotics exposure & - & Bifidobacterium, and F. prausnitzii & [84, 85] \\
C. difficile infection & Lactobacillus, and Clostridia & Bacteroides, Prevotella and Bifidobacteria & [87, 86] \\
\hline
\end{tabular}

microbiota composition due to antibiotics exposure enforced a reduction in abundance of Bifidobacterium and $F$. prausnitzii with a nominal effect on the overall microbiota. Similarly, elderly subjects were examined to check the variations in gut microbiota due to aging with and without infection of $C$. difficile in the gut. The results have demonstrated that the gut microbiota of elderly subjects is altered as increment in abundance and diversity of Bacteroides species and decrement in diversity of Bifidobacteria (Table 2) $[84,85]$. In a comparative study, the gut microbiota in elders with $C$. difficile infections showed higher diversity of Lactobacillus and Clostridia, and lower diversity of Bacteroides, Prevotella and Bifidobacteria. It is believed that alteration in the gut microbiota during aging provide a favorable environment for growth of pathogens in the gut. The use of prebiotics or probiotics could maintain a beneficial diversity of intestinal microbes, which could prevent or delay $C$. difficile infections in aging subjects $[86,87]$.

\section{Impact of diet on the human gut microbiota}

Through decades of research on the gut microbiota it has been postulated that dietary substrates play vital roles in altering the gut microbiota composition and its functional capabilities [88, 89]. However, the precise mechanisms behind changes in the gut microbiota due to consumption of different diets, is still an open research question. More precisely, short-term and long-term dietary patterns act differently to trigger the variations in composition and functional modules of the microbiota [90]. A recent study has revealed the capability of the intestinal microbiota to alter and reshape its composition rapidly by variation in diet for a short time (five consecutive days) [45]. In this study, animaland plant-based diets were selected to examine the variations and reproducibility in the gut microbiota of 10 American volunteers between the age of 21 and 33. Results demonstrated that the abundance of biletolerant microorganisms such as Alistipes, Bilophila and Bacteroides increased during animal-based diet consumption, while a decrease was noticed in the abundance of Firmicutes involved in metabolizing dietary plant polysaccharides (Roseburia, Eubacterium rectale and Ruminococcus bromii) (Fig. 3). However, it was found that short-term dietary patterns remained ineffective in triggering significant changes in 'enterotypes' [90], which are defined as three clusters of genera dominated by Bacteroides, Prevotella, and Ruminococcus [91]. This study also suggested that introduction of high-fat/low-fiber or low-fat/high-fiber diet initialized changes in the gut microbiota within 24 hours, but the enterotype of the subjects remained stable for up to 10 days. Further, examinations of long-term dietary interventions have demonstrated strong association with alteration in enterotypes.

Capabilities of the human gut microbiota for rapid shift in its composition and metabolic functionality could be connected with human evolution over the unavailability of similar food sources over time [92]. Perhaps, availability of animal-based food was always dependent on success in hunting, whereas alternative sessional plant-based foods were consumed more frequently. These rapid changes in diets would have increased the selective pressure for enhancing the flexibility of functional modules of the gut microbiota [93]. In modern diet patterns, several studies have suggested that variations in the gut microbiota due to animal-based diets could be responsible for alteration in bile acid biosynthesis [94-96]. Experimental studies, using mouse as a model host, showed that animal-based/high-fat diets initiate a high production of a particular secondary bile acid, namely, deoxycholic acid, which is involved in promoting liver cancer. It has also been noticed that high-fat diets may stimulate the growth of Bilophila wadsworthia (a sulphite-reducing bacterium), which is one of the cues for causing Inflammatory Bowel Disease (IBD) [97-99].

In contrast, plant-based diets have a higher fiber content than animal-based diets and microbial fermentation of dietary polysaccharides can provide up to $10 \%$ of the energy intake by human $[100,101]$. 

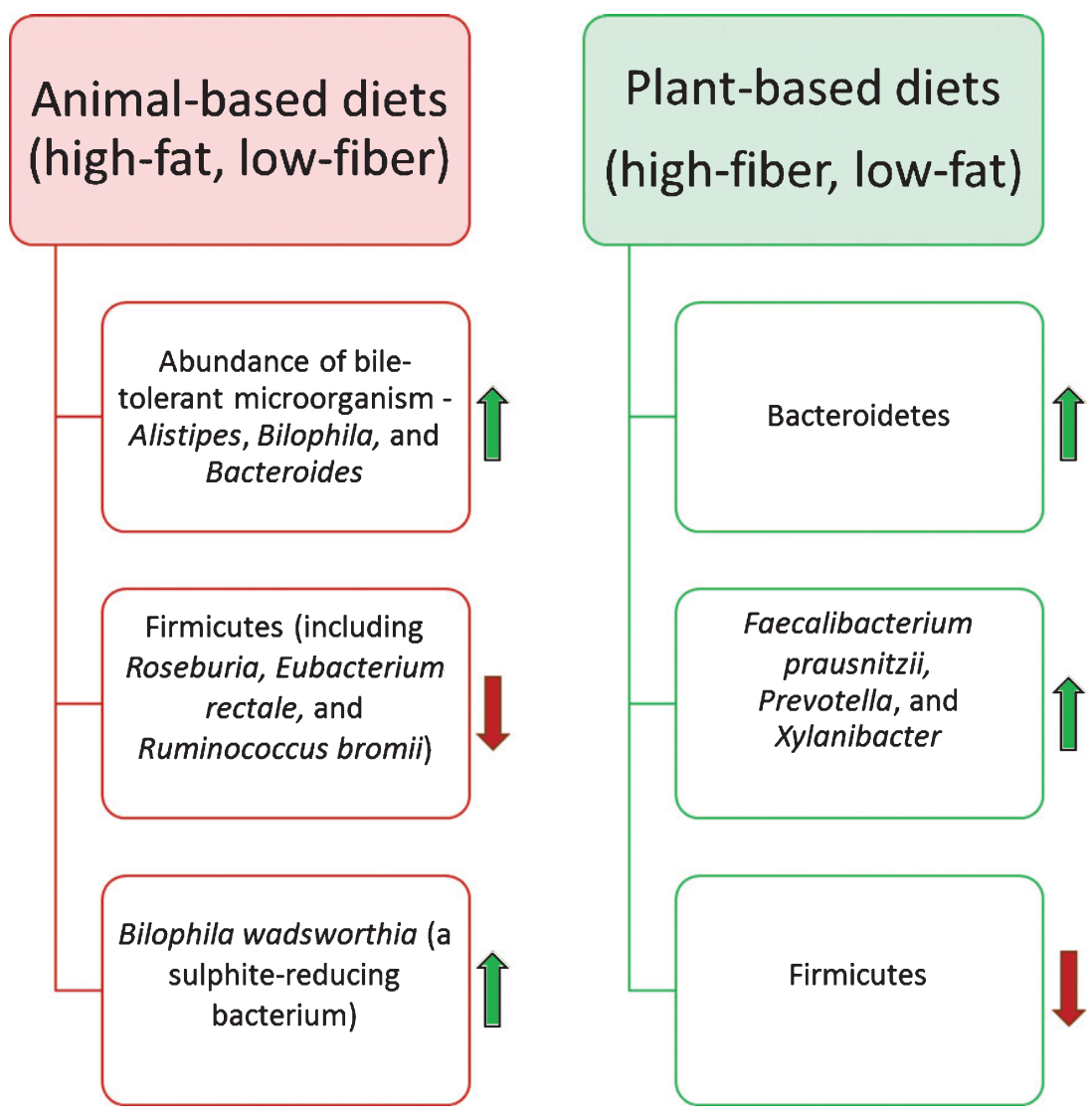

Fig. 3. Impact of the diet on the human gut microbiota composition. Diet is one of the most influential factors for altering the composition of the gut microbiota. Animal-based diets promote the growth of bile-tolerate microorganisms. In contrast, plant-based diets elevate the abundance of polysaccharides-digesting bacterial species.

Moreover, a high-fiber content diet stimulates variations in the gut microbiota towards performing several beneficial functions such as protection from inflammation, obesity, diabetes, heart disease, and high blood pressure [102, 103]. Turnbaugh et al. have performed a comparative study to determine the impact of diet on host physiology by switching the low-fat, plant polysaccharides-rich diet to a high-fat, high-sugar diet in germ-free mice colonized with a human gut microbiome. Results of this study demonstrated that change in the diet within a day altered gene expressions of the gut microbiome and metabolic pathways. It has been reported that diets with high-fiber content enrich the abundance of Bacteroidetes and decrease the abundance of Firmicutes $[41,89]$. In a study by Filippo et al., the fecal microbiota of children from Europe and an African village of Burkina Faso (BF) were compared, considering the significant differences in diets of both cohorts. Interestingly, a unique abundance of genus Prevotella and Xylanibacter was noticed during the consumption of high-fiber containing food. These genus express genes involved in cellulose and xylan hydrolysis. Findings of this study also postulated that fiber-containing diets can help in developing the gut microbiota towards protecting the host from inflammation and noninfectious colonic diseases, due to the high abundance of Faecalibacterium prausnitzii along with other Short Chain Fatty Acids (SCFAs) producing bacteria [41, 104]. Similarly, some studies have shown that low abundance of $F$. prausnitzii correlated with Crohn Disease (CD) and IBD [25, 105]. Furthermore, various studies have suggested that butyrate, one of the products of SCFAs-producing bacteria, could play several beneficial roles to improve the health in elderly $[67,106]$. For instance, Govindarajan et al. have noticed that sodium butyrate enhances the memory function in mice models of Alzheimer's disease at an advance stage of age progression [107]. 


\section{Effect of age-related alteration in gut microbiota on human health}

One of the severe effects of the age-related changes in composition of gut microbiota is increment in the abundance of Gram-negative bacteria, like Enterobacteriaceae and other pathogens [1]. These Gram-negative bacteria have capability to secrete lipopolysaccharides, which may act as endotoxin. Lipopolysaccharide is a carbohydrate-fat complex, that may cause inflammation in gut [2-4]. It has been postulated that the level of SCFAs, especially acetate, butyrate, and propionate, in the intestine of aged people is reduced compared to young subjects [5]. This may lead to secretion of mucins by the intestinal epithelial cells, which, in turn, allows entry of pathogens easily into the intestinal mucosa [1]. Therefore, the synthesis of SCFAs by gut microbiota is considered as anti-inflammatory activity to reduce the causes of diseases like CD and IBD [6]. To this end, diet interventions using fiber-rich diets or indigestible-carbohydrates promote the production of SCFAs through fermentation by gut bacteria. Several studies have suggested that acetate is mainly absorbed and metabolized in brain, kidney, muscles, and heart $[7,8]$. Propionate is metabolized by liver and might play a role as an inhibitor for cholesterol synthesis, which is connected to regulation of adipose tissue deposition $[9,10]$. On the other hand, butyrate is mostly absorbed by the colonic epithelial cell and work as an energy source. It also plays an important role in cell growth and differentiation as well as in reducing the risk of colon cancer by stimulating apoptosis [11, 12].

The age-related decline in SCFAs production by the gut microbiota of elderly can hamper the immune system, which cause several gut-related diseases in aged human subjects. In this direction, Arpaia et al., demonstrated that butyrate improves the antiinflammatory activity of the immune system [13]. In another study, it has been noticed that epigenetic modifications in immune cells i.e. macrophages by butyrate reduces the secretion of inflammatory factors such as IL-6 [14]. This leads to a reduction of the permeability of the mucosal membrane to lessen the infiltration of harmful molecules, like lipopolysaccharides from the colon [15]. Similarly, some studies have demonstrated the anti-inflammatory activities of acetate and propionate $[16,17]$. Furthermore, more research efforts are required in this area to fill the knowledge gaps between age-related changes in the microbial ecology of gut and human health. Such studies will reveal more specific targets for therapeutic interventions to treat or delay the gut-related diseases in elderly.

\section{How to maintain beneficial gut microbiota for healthy aging?}

The factors which influence composition and functionality of the gut microbiota are vital because of beneficial roles of these microbes towards maintaining health and preventing certain diseases in elderly people [47]. The diet is one of the most important factors, which can modulate the gut microbiota on the basis of nutritional substrates present/absent in the diet [45]. For instance, vitamin D is very critical during the aging process owing to the reduction in biosynthesis of cholecalciferol (vitamin D) from 7 dehydrocholesterol in skin after sun exposure. It has been observed that the level of 7-dehydrocholestrol in older people is decreased compare to younger people [108]. Moreover, vitamin D deficiency causes a negative impact on calcium homeostasis or calcium absorption in old age. Furthermore, some studies has postulated that vitamin D deficiency also alters the gut microbiota, which leads to irregularity in the immune system $[40,109]$. Similarly, it has been noticed that elderly people consume low amount of fibrous diet because of reduction in taste sensation and olfaction. This change in diet causes negative impact on gut microbiota diversity [110]. Precisely, species diversity of Bifidobacteria deceases during the old age [84, 85]. To this end, fiber intake is very important for elderly because fibrous substrates act as prebiotics for developing a beneficial gut microbiota.

Consumption of prebiotics/probiotics along with a nutritious diet stimulates the growth and functionality of bacterial species in the gut microbiota for health benefits during the old age. Prebiotics are selective fermented ingredients or non-digestible food ingredients, which promote growth and activities of the selective bacterial species in the gut microbiota for maintaining health (Table 3) $[111,112]$. Most common examples of prebiotics are mannooligosaccharides (MOS), galactooligosaccharides (GOS) [113, 114], inulin, lactulose [115], fructo-oligosaccharides (FOS) [116], pectic-oligosaccharides (POS) [117, 118], xylooligosaccharides (XOS) [119], and transgalactosylatedoligosaccharides (TOS) [120]. In prebiotics based studies, different combinations of prebiotics have been examined in elderly. For instance, use of inulin and its derivatives (FOS) has 
Table 3

Prebiotics tested for preventing or delaying the gut-related diseases in elderly

\begin{tabular}{llc}
\hline Abbreviation & Prebiotics name & References \\
\hline MOS & Mannooligosaccharides & {$[113,114]$} \\
GOS & Galactooligosaccharides & {$[113,114]$} \\
- & inulin & {$[115]$} \\
- & Lactulose & {$[115]$} \\
FOS & Fructo-oligosaccharides & {$[117,118]$} \\
POS & Pectic-oligosaccharides & {$[117,118]$} \\
XOS & Xylooligosaccharides & {$[119]$} \\
TOS & Transgalactosylatedoligosaccharides & {$[120]$} \\
\hline
\end{tabular}

demonstrated an increment in abundance of Bifidobacteria, which led to reduction in markers of inflammation and increment in stool frequency [115, 121-124]. Similar to prebiotics, probiotics illustrate the potentials for promoting the growth of beneficial species in an aging gut microbiota [112]. Probiotics are live microbes supplements, which maintain the microbial balance in the gut to promote the health benefits [125]. In the case of elderly, Bifidobacteria species were examined as these species decreased during aging [46, 126]. Results demonstrated beneficial changes in terms of increasing stool frequency and preventing inflammation [127]. Although, current selection of probiotics is still limited to physiological characteristics of species like viability and stability instead of health benefits. Microbes cross a highly unfavorable environment such as low $\mathrm{pH}$ zone in the stomach and high concentration of bile salts in the gastrointestinal tract [128-130]. This limitation of probiotics could be defined as survival of microbes during their delivery to the intestine [131]. Therefore, investigation of novel probiotics and their delivery systems can extend the application of probiotics towards enhancing the health benefits to health in elderly people.

\section{Recent research efforts to understand the functionality of the gut microbiota}

Previous studies on the gut microbiota have mainly analyzed the abundance at phylum/genus-level and to some extent at species-level in different age groups (infants, adults, and elders) in various countries during health and diseases. Recent studies, however, are focused on investigating the specieslevel functional behaviors of microbes in the gut microbiota. Due to limitations of current experimental techniques, computer-based methods can help to understand the metabolic behavior of intestinal bacterial species as well as microbe-microbe, microbe-host, and diet-microbe interactions in the community level. One way to study the human gut microbiota is constraint-based modeling [132, 133]. In constraint-based modeling, the metabolic information of a particular organism is presented by a genome-scale metabolic model (GEM). The core element of a GEM is a stoichiometric matrix representing information about the stoichiometry of all metabolic reactions in the organism. Furthermore, each reaction is linked to an enzyme and its corresponding gene, and GEMs hereby provide a gene-protein-reaction connectivity. There is also a biomass reaction in GEMs, which describes how metabolites required for building macromolecules forming the basis of the biomass are being consumed. Through the stoichiometric matrix metabolism is represented in a machine-readable form and different computational analysis can be carried out using the matrix. By optimizing the cellular biomass production it is possible to calculate the metabolic flux through each reaction using the concept of flux balance analysis (FBA) which in turn enables cellular phenotypic predictions in the context of the organism's genetic and environmental boundaries [134, 135].

GEMs have been used in order to get a deeper understanding of the interplay between genotype and phenotype. These mathematical models can also be used to simulate microbial communities like the human gut microbiota. In this direction, genome-scale metabolic modeling approaches have demonstrated potential capabilities towards enhancement in understanding of phenotypic characteristics of the gut microbiota [136, 137]. Since the population of the gut related bacteria is very large, more efforts are required to develop high-quality GEMs in this area. Moreover, research efforts towards exploring uncharacterized genomes of bacterial species in gut microbiome, will be easy to incorporate into this GEMs approach for predicting the metabolic behavior of members of gut microbiota as modeling of the microbial community can easily be expanded to consider metabolism also of newly identified species [138].

Metabolic models have been widely used to decipher the genotype-phenotype relationships in single species. These models can also be used to study microbial communities, although in order to simulate a multispecies system like the human gut microbiota, formulating the inter-species interactions and 
the objective function is of crucial importance. One way to simulate a microbial consortium is to consider each member of the community as a separate compartment. These compartments interact with each other in terms of metabolite exchanges through a shared compartment. Another element that greatly influences in silico predictions is the objective function. When dealing with a single species metabolic network, the objective function is usually defined as the flux through a reaction, which is considered to represent cellular growth. The objective function of a community, however, is more complicated. Another way to simulate a community is to separate the organism-level and community-level objective functions, as implemented in a recent study using a method called CASINO [82]. The CASINO optimization algorithm integrates well with diet analysis and can hereby be used to understand the metabolic microbe-microbe, diet-microbe and hostmicrobe interactions. In a recent study, CASINO was used to elucidate metabolic interactions between the microbiota in the small intestine of mice and different tissues [139]. The goal was to investigate the metabolic differences in the small intestine of conventionally raised mice compared to the germ-free ones. The amount of consumed amino acids and produced short-chain fatty acids by the bacteria were calculated and found to be consistent with the experimental observations [139].

\section{Conclusions and future perspectives}

Aging is defined as deterioration of physiological functions accompanied by the development of age [18]. Older people ( $>65$ years) are more susceptible to age-related diseases and disabilities. Currently, one of the goals for scientific and social communities is to explore novel strategies for improving health in old aging, which can be achieved by preventing age-associated diseases. This step could aid in improving socio-economic conditions and reducing the cost of healthcare in an aging population. The human gastrointestinal tract harbors a vast ensemble of microbes, which benefit the host through its metabolic phenotypes. The influences of aging process on the alterations of gut microbiota composition and function is of particular interest in gut microbiota studies, as well as the effects of aging on the human host in genetics or epigenetics. Recently, correlations between the gut microbiota and aging was investigated in several studies and these show that aging can affect the composition and metabolic functions of gut bacterial species, and further that this alteration can be associated with numerous gutrelated disease in the host. Therefore, maintaining a beneficial microbial community in the gut may help to prevent or delay age-associated diseases. Increased understanding of the contributions of the gut microbiota to human healthy had resulted in attempts to manipulate its composition by the use of prebiotics/probiotics or introduce new gut microbial species by fecal microbiota transplantation. Furthermore, a healthy diet is one of the strategies that can be employed to improve health during aging and some preliminary reports, based on effect of plant-based diets on gut microbiota [111,112], has shown a path to design more effective diets to maintain healthy aging. Genome-scale metabolic model driven modeling can be used to simulate the effects of diet on the gut microbiota composition and its interaction with human metabolism, and can hereby provide an effective and quick way to screen putative diet components suitable for older people. Moreover, the administration of probiotics/probiotics to elderly had been shown to alter the composition and functionality of the gut microbiota. GEM-driven modeling can also be used to identify candidate species for probiotic design by in-silico analysis of metabolic capacities and interactions of gut microbial species [140]. Application of these mathematical modeling approaches have the potential to become a useful support to develop personalized probiotics or nutritional strategies [141] to maintain the healthy status of the aging people. In this direction, the main hurdle is poorly known metabolic connections between diet, microbes, and host. To study these complex connections, computational tools, such as genome scale metabolic modeling, can be employed.

\section{Acknowledgments}

This work was financially supported by the Knut and Alice Wallenberg Foundation and the Bill \& Melinda Gates Foundation.

\section{References}

[1] Schiffrin EJ, Morley JE, Donnet-Hughes A, Guigoz Y. The inflammatory status of the elderly: The intestinal contribution. Mutat Res - Fundam Mol Mech Mutagen [Internet]. Elsevier B.V.; 2010;690(1-2):50-6. Available from: http://dx.doi.org/10.1016/j.mrfmmm.2009.07.011 
[2] Silhavy TJ, Kahne D, SW. The bacterial cell envelope. Cold Spring Harb Perspect Biol. 2010;2(5):1-16.

[3] Sheu CW, Freese E. Lipopolysaccharide layer protection of gram-negative bacteria against inhibition by long-chain fatty acids. J Bacteriol. 1973;115(3):869-75.

[4] Rhee SH. Lipopolysaccharide: Basic biochemistry, intracellular signaling, and physiological impacts in the gut. Intest Res [Internet]. 2014;12(2):90-5. Available from: http://synapse.koreamed.org/search.php?where=aview\&id $=10.5217 /$ ir $.2014 .12 .2 .90 \&$ code $=0143$ IR $\&$ vmode $=$ FULL

[5] Biagi E, Nylund L, Candela M, Ostan R, Bucci L, Pini E, et al. Through ageing, and beyond: Gut microbiota and inflammatory status in seniors and centenarians. PLoS One [Internet]. 2010;5(5):e10667. Available from: http://dx.plos.org/10.1371/journal.pone.0010667

[6] De Vuyst L, Leroy F. Cross-feeding between bifidobacteria and butyrate-producing colon bacteria explains bifdobacterial competitiveness, butyrate production, and gas production. Int $\mathrm{J}$ Food Microbiol [Internet]. Elsevier B.V.; 2011;149(1):73-80. Available from: http://dx.doi.org/10.1016/j.ijfoodmicro.2011.03.003

[7] Vogt JA, Wolever TM. Fecal acetate is inversely related to acetate absorption from the human rectum and distal colon. J Nutr [Internet]. 2003;133(10):3145-8. Available from: http://www.ncbi.nlm.nih.gov/entrez/query.fcgi?cmd=Retri eve \&db=PubMed\&dopt=Citation\&list_uids=14519799

[8] Cummings JH. Short chain fatty acids in the human colon. Gut [Internet]. 1981;22(9):763-79. Available from: http://gut.bmj.com/cgi/doi/10.1136/gut.22.9.763

[9] Reshef L, Niv J, Shapiro B. Effect of propionate on lipogenesis in adipose tissue. J Lipid Res [Internet]. 1967;8(6):682-7. Available from: http://www.ncbi.nlm.nih. gov/pubmed/6057497

[10] Xiong Y, Miyamoto N, Shibata K, Valasek MA, Motoike T, Kedzierski RM, et al. Short-chain fatty acids stimulate leptin production in adipocytes through the $\mathrm{G}$ protein-coupled receptor GPR41. Proc Natl Acad Sci U S A [Internet]. 2004;101(4):1045-50. Available from: http://www.pubmedcentral.nih.gov/articlerender.fcgi?artid $=327148 \&$ tool $=$ pmcentrez $\&$ rendertype $=$ abstract

[11] Scheppach W. Treatment of distal ulcerative colitis with short-chain fatty acid enemas. A placebo-controlled trial. German-Austrian SCFA Study Group. Dig Dis Sci. 1996;41(11):2254-9.

[12] Williams EA, Coxhead JM, Mathers JC. Anti-cancer effects of butyrate: Use of micro-array technology to investigate mechanisms. Proc Nutr Soc [Internet]. 2003;62(1):10715. Available from: http://www.ncbi.nlm.nih.gov/pubmed/ 12740065

[13] Arpaia N, Campbell C, Fan X, Dikiy S, van der Veeken J, deRoos P, et al. Metabolites produced by commensal bacteria promote peripheral regulatory T-cell generation. Nature [Internet]. Nature Publishing Group. 2013;504(7480):4515. Available from: http://www.pubmedcentral.nih.gov/arti clerender.fcgi?artid=3869884\&tool=pmcentrez\&renderty pe $=$ abstract

[14] Chang PV, Hao L, Offermanns S, Medzhitov R. The microbial metabolite butyrate regulates intestinal macrophage function via histone deacetylase inhibition. Proc Natl Acad Sci. 2014;111(6):2247-52.

[15] Monolayers C-C, Peng L, Li Z, Green RS, Holzman IR, Lin J. Butyrate Enhances the Intestinal Barrier by Facilitating
Tight Junction Assembly via Activation of AMP-Activated Protein Kinase. 2009;1619-25.

[16] Tedelind S, Westberg F, Kjerrulf M, Vidal A. Antiinflammatory properties of the short-chain fatty acids acetate and propionate: A study with relevance to in $\mathrm{fl}$ flammatory bowel disease. World J Gastroenterol. 2007; 13(20):2826-32.

[17] Scarpellini E, Lauritano EC, Lupascu A, Petruzzellis C, Novi ML, Roccarina D, et al. Efficacy of butyrate in the treatment of diarrhoea-predominant irritable bowel syndrome. Dig Liver Dis Suppl. Editrice Gastroenterologica Italiana S.r.1. 2007;1(1):19-22.

[18] Imahori K. How I understand aging. Nutr Rev [Internet]. 1992;50(12):351-2. Available from: http://www.ncbi. nlm.nih.gov/pubmed/1488164

[19] Britton E, McLaughlin JT. Ageing and the gut. Proc Nutr Soc [Internet]. 2013;72(1):173-7. Available from: http://www.ncbi.nlm.nih.gov/pubmed/23146206

[20] Claesson MJ, Jeffery IB, Conde S, Power SE, O'Connor EM, Cusack S, et al. Gut microbiota composition correlates with diet and health in the elderly. Nature [Internet]. 2012;488(7410):178-84. Available from: http://www.nat ure.com/nature/journal/v488/n7410/full/nature11319.html \#contrib-auth

[21] Rampelli S, Candela M, Turroni S, Collino EB, Franceschi $\mathrm{C}$, O'Toole PW, et al. Functional metagenomic profiling of intestinal microbiome in extreme ageing. Aging (Albany NY). 2013;5(12):902-12.

[22] Clemente JC, Ursell LK, Parfrey LW, Knight R. The impact of the gut microbiota on human health: An integrative view. Cell [Internet]. Elsevier Inc.; 2012;148(6):1258-70. Available from: http://ac.els-cdn.com/S0092867412001043/ 1-s2.0-S0092867412001043-main.pdf?_tid=8fe745ac-e4 21-11e4-94a4-00000aacb35f\&acdnat=1429179532_80871 71a9a4ca52d2b5d77ac796ab2b0 \nhttp://www.ncbi.nlm. nih.gov/pubmed/22424233

[23] Gruver AL, Hudson LL, Sempowski GD. Immunosenescence of ageing. J Pathol. 2007;211(2):144-56.

[24] Ley R, Turnbaugh P, Klein S, Gordon J. Microbial ecology: Human gut microbes associated with obesity. Nature [Internet]. 2006;444(7122):1022-3. Available from: http://europepmc.org/abstract/MED/17183309

[25] Frank DN, St Amand AL, Feldman RA, Boedeker EC, Harpaz N, Pace NR. Molecular-phylogenetic characterization of microbial community imbalances in human inflammatory bowel diseases. Proc Natl Acad Sci U S A [Internet]. 2007;104(34):13780-5. Available from: http:// www.pubmedcentral.nih.gov/articlerender.fcgi?artid=1959 459\& tool=pmcentrez\&rendertype $=$ abstract

[26] Qin J, Li R, Raes J, Arumugam M, Burgdorf KS, Manichanh $\mathrm{C}$, et al. A human gut microbial gene catalogue established by metagenomic sequencing. Nature [Internet]. 2010;464(7285):59-65. Available from: http:// dx.doi.org/10.1038/nature08821

[27] Kassinen A, Krogius-Kurikka L, Mäkivuokko H, Rinttilä T, Paulin L, Corander J, et al. The fecal microbiota of irritable bowel syndrome patients differs significantly from that of healthy subjects. Gastroenterology. 2007;133(1): 24-33.

[28] Jeffery IB, O’ Toole PW, Ohman L, Claesson MJ, Deane J, Quigley EMM, et al. An irritable bowel syndrome subtype defined by species-specific alterations in faecal micro- 
biota. Gut [Internet]. 2012;61(7):997-1006. Available from: http://gut.bmj.com/cgi/doi/10.1136/gutjnl-2011-301501

[29] Brugman S, Klatter FA, Visser JTJ, Wildeboer-Veloo ACM, Harmsen HJM, Rozing J, et al. Antibiotic treatment partially protects against type 1 diabetes in the Bio-Breeding diabetes-prone rat. Is the gut flora involved in the development of type 1 diabetes? Diabetologia [Internet]. 2006;49(9):2105-8. Available from: http://link. springer.com/10.1007/s00125-006-0334-0

[30] Qin J, Li Y, Cai Z, Li SS, Zhu J, Zhang F, et al. A metagenome-wide association study of gut microbiota in type 2 diabetes. Nature [Internet]. Nature Publishing Group; 2012;490(7418):55-60. Available from: http://www.nature.com/nature/journal/v490/n7418/full/nat ure11450.html \nhttp://www.nature.com/nature/journal/ v490/n7418/pdf/nature11450.pdf

[31] Wen L, Ley RE, Volchkov PY, Stranges PB, Avanesyan $\mathrm{L}$, Stonebraker AC, et al. Innate immunity and intestinal microbiota in the development of Type 1 diabetes. Nature [Internet]. 2008;455(7216):1109-13. Available from: http://www.nature.com/doifinder/10.1038/nature07336

[32] Karlsson FH, Tremaroli V, Nookaew I, Bergström G, Behre CJ, Fagerberg B, et al. Gut metagenome in European women with normal, impaired and diabetic glucose control. Nature [Internet]. 2013;498(7452):99-103. Available from: http://www.nature.com/doifinder/10.1038/nature12198

[33] Koren O, Spor A, Felin J, Fak F, Stombaugh J, Tremaroli $\mathrm{V}$, et al. Human oral, gut, and plaque microbiota in patients with atherosclerosis. Proc Natl Acad Sci [Internet]. 2011;108(Supplement_1):4592-8. Available from: http://www.pnas.org/cgi/doi/10.1073/pnas.1011383107

[34] Karlsson FH, Fåk F, Nookaew I, Tremaroli V, Fagerberg B, Petranovic D, et al. Symptomatic atherosclerosis is associated with an altered gut metagenome. Nat Commun [Internet]. Nature Publishing Group, a division of Macmillan Publishers Limited. All Rights Reserved.; 2012 Dec 4 [cited 2015 Sep 27];3:1245. Available from: http://dx.doi.org/10.1038/ncomms2266

[35] Kirjavainen PV, Arvola T, Salminen SJ, Isolauri E. Aberrant composition of gut microbiota of allergic infants: A target of bifidobacterial therapy at weaning? Gut. 2002;51(1): 51-5.

[36] Cryan JF, Dinan TG. Mind-altering microorganisms: The impact of the gut microbiota on brain and behaviour. Nat Rev Neurosci [Internet]. Nature Publishing Group. 2012;13(10):701-12. Available from: http://www. ncbi.nlm.nih.gov/pubmed/22968153

[37] Spor A, Koren O, Ley R. Unravelling the effects of the environment and host genotype on the gut microbiome. Nat Rev Microbiol [Internet]. Nature Publishing Group; 2011;9(4):279-90. Available from: http://www. nature.com/doifinder/10.1038/nrmicro2540

[38] Neish AS. Microbes in gastrointestinal health and disease. Gastroenterology. 2009;136(1):65-80.

[39] Hildebrandt MA, Hoffman C, Sherrill-mix SA, Keilbaugh SA, Chen Y, Knight R, et al. High fat diet determines the composition of the murine gut microbiome independently of obesity. Gastroenterology. 2009;137(5):1716-24.

[40] Mai V, McCrary QM, Sinha R, Glei M. Associations between dietary habits and body mass index with gut microbiota composition and fecal water genotoxicity: An observational study in African American and Caucasian
American volunteers. Nutr J [Internet]. 2009;8(1):49. Available from: http://www.nutritionj.com/content/8/1/49

[41] De Filippo C, Cavalieri D, Di Paola M, Ramazzotti M, Poullet JB, Massart S, et al. Impact of diet in shaping gut microbiota revealed by a comparative study in children from Europe and rural Africa. Proc Natl Acad Sci [Internet]. 2010;107(33):14691-6. Available from: http:// www.pnas.org/cgi/doi/10.1073/pnas.1005963107

[42] Turnbaugh PJ, Ridaura VK, Faith JJ, Rey FE, Knight R, Gordon JI. The effect of diet on the human gut microbiome: A metagenomic analysis in humanized gnotobiotic mice. Sci Transl Med [Internet]. 2009;1(6):6ra14. Available from: http://stm.sciencemag.org/content/1/6/6ra14.short

[43] Faith JJ, McNulty NP, Rey FE, Gordon JI. Predicting a human gut microbiota's response to diet in gnotobiotic mice. Science [Internet]. 2011;333(6038):1014. Available from: http://www.sciencemag.org/content/ 333/6038/101.long

[44] Muegge BD, Kuczynski J, Knights D, Clemente JC, González A, Fontana L, et al. Diet drives convergence in gut microbiome functions across mammalian phylogeny and within humans: Supplementary Material. Science (80-). 2011;332(6032):970-4.

[45] David LA, Maurice CF, Carmody RN, Gootenberg DB, Button JE, Wolfe BE, et al. Diet rapidly and reproducibly alters the human gut microbiome. Nature [Internet]. Nature Publishing Group. 2014;505(7484):559-63. Available from: http://www.pubmedcentral.nih.gov/articlerender.fc gi?artid=3957428\&tool=pmcentrez\&rendertype $=$ abstract

[46] Di Gioia D, Aloisio I, Mazzola G, Biavati B. Bifidobacteria: Their impact on gut microbiota composition and their applications as probiotics in infants. Appl Microbiol Biotechnol [Internet]. 2014;98(2):563-77. Available from: http://www.ncbi.nlm.nih.gov/pubmed/24287935

[47] Human Microbiome Project Consortium T. Structure, function and diversity of the healthy human microbiome. Nature [Internet]. Nature Publishing Group. 2012;486(7402):20714. Available from: http://dx.doi.org/10.1038/nature11234

[48] Zhang H, Sparks JB, Karyala SV, Settlage R, Luo XM. Host adaptive immunity alters gut microbiota. ISME J [Internet]. Nature Publishing Group. 2015;9(3):770-81. Available from: http://www.nature.com/ doifinder/10.1038/ismej.2014.165

[49] Yatsunenko T, Rey FE, Manary MJ, Trehan I, DominguezBello MG, Contreras M, et al. Human gut microbiome viewed across age and geography. Nature. 2012;486:222-7.

[50] Costello E, Lauber C, Hamady M, Fierer N, Gordon JI, Knight R. Bacterial community variation in human body habitats across space and time. Science (80-). 2009;326(December):1694-7.

[51] Fouhy F, Ross RP, Fitzgerald GF, Stanton C, Cotter PD. Composition of the early intestinal microbiota: Knowledge, knowledge gaps and the use of high-throughput sequencing to address these gaps. Gut Microbes. 2012;3(June):203-20.

[52] Huurre A, Kalliomäki M, Rautava S, Rinne M, Salminen $\mathrm{S}$, Isolauri E. Mode of delivery - Effects on gut microbiota and humoral immunity. Neonatology. 2008;93(October 2015):236-40.

[53] Li Y, Caufield PW, Dasanayake a P, Wiener HW, Vermund $\mathrm{SH}$. Mode of delivery and other maternal factors influence the acquisition of Streptococcus mutans in infants. J Dent Res. 2005;84(9):806-11. 
[54] Salminen S, Gibson GR, McCartney AL, Isolauri E. Influence of mode of delivery on gut microbiota composition in seven year old children. Gut [Internet]. 2004;53(9):1388-9. Available from: http://www.pubmed central.nih.gov/articlerender.fcgi?artid=1774211\&tool= pmcentrez\&rendertype $=$ abstract

[55] Ajslev TA, Andersen CS, Gamborg M, Sørensen TIA, Jess T. Childhood overweight after establishment of the gut microbiota: The role of delivery mode, prepregnancy weight and early administration of antibiotics. Int J Obes [Internet]. 2011;35(4):522-9. Available from: http://www.nature.com/doifinder/10.1038/ijo.2011.27

[56] Zeissig S, Blumberg RS. Life at the beginning: Perturbation of the microbiota by antibiotics in early life and its role in health and disease. Nat Immunol [Internet]. Nature Publishing Group. 2014;15(4):307-10. Available from: http://dx.doi.org/10.1038/ni.2847\nfile:///Users/fingolfn/ Dropbox/Papers2/Articles/2014/Zeissig/NatImmunol2014 Zeissig.pdf $\backslash$ npapers2://publication/doi/10.1038/ni.2847

[57] Schulfer A, Blaser MJ. Risks of Antibiotic Exposures Early in Life on the Developing Microbiome. PLOS Pathog [Internet]. 2015;11(7):e1004903. Available from: http://dx.plos.org/10.1371/journal.ppat.1004903

[58] Saari A, Virta LJ, Sankilampi U, Dunkel L, Saxen H. Antibiotic Exposure in Infancy and Risk of Being Overweight in the First 24 Months of Life. Pediatrics [Internet]. 2015;135(4):617-26. Available from: http:// pediatrics.aappublications.org/cgi/doi/10.1542/peds.20143407

[59] Adlerberth I, Wold A. Establishment of the gut microbiota in Western infants. Acta Paediatr [Internet]. 2009;98(2):229-38. Available from: http://doi.wiley. com/10.1111/j.1651-2227.2008.01060.x

[60] Le Huërou-Luron I, Blat S, Boudry G. Breast- v. formulafeeding: Impacts on the digestive tract and immediate and long-term health effects. Nutr Res Rev. 2010;23(1): 23-36.

[61] Penders J, Thijs C, Vink C, Stelma FF, Snijders B, Kummeling I, et al. Factors influencing the composition of the intestinal microbiota in early infancy. Pediatrics [Internet]. 2006;118(2):511-21. Available from: http:// pediatrics.aappublications.org/cgi/doi/10.1542/peds.20052824

[62] Troen B. The biology of aging. Mt Sinai J Med. 2003;70(1):3-22.

[63] Biagi E, Candela M, Turroni S, Garagnani P, Franceschi C, Brigidi P. Ageing and gut microbes: Perspectives for health maintenance and longevity. Pharmacol Res [Internet]. Elsevier Ltd; 2013;69(1):11-20. Available from: http://dx.doi.org/10.1016/j.phrs.2012.10.005

[64] Zierer J, Menni C, Kastenmu G, Spector TD. Integration of "omics" data in aging research: From biomarkers to systems biology Jonas. Aging Cell. 2015;1-12.

[65] Park S-H, Kim K-A, Ahn Y-T, Jeong J-J, Huh C-S, Kim D-H. Comparative analysis of gut microbiota in elderly people of urbanized towns and longevity villages. BMC Microbiol [Internet]. 2015;15(1):49. Available from: http://www.biomedcentral.com/1471-2180/15/49

[66] Hollister EB, Riehle K, Luna RA, Weidler EM, Rubio-Gonzales M, Mistretta T-A, et al. Structure and function of the healthy pre-adolescent pediatric gut microbiome. Microbiome [Internet]. Microbiome; 2015;
3(1):36. Available from: http://www.microbiomejournal com/content $/ 3 / 1 / 36$

[67] Keenan MJ, Marco ML, Ingram DK, Martin RJ. Improving healthspan via changes in gut microbiota and fermentation. Age (Omaha) [Internet]. 2015;37(5):98. Available from: http://link.springer.com/10.1007/s11357-015-9817-6

[68] Sonnenburg ED, Sonnenburg JL. Starving our microbial self: The deleterious consequences of a diet deficient in microbiota-accessible carbohydrates. Cell Metab [Internet]. Elsevier Inc.; 2014;20(5):779-86. Available from: http://dx.doi.org/10.1016/j.cmet.2014.07.003

[69] Biagi E, Candela M, Fairweather-Tait S, Franceschi C, Brigidi P. Ageing of the human metaorganism: The microbial counterpart. Age (Omaha) [Internet]. 2012;34(1):24767. Available from: http://link.springer.com/10.1007/ s11357-011-9217-5

[70] Palmer C, Bik EM, DiGiulio DB, Relman DA, Brown PO. Development of the human infant intestinal microbiota. PLoS Biol [Internet]. 2007;5(7):e177. Available from: http: //biology.plosjournals.org/perlserv/?request=get-docu ment\&doi=10.1371\%2Fjournal.pbio.0050177

[71] Koenig JE, Spor A, Scalfone N, Fricker AD, Stombaugh $\mathrm{J}$, Knight R, et al. Succession of microbial consortia in the developing infant gut microbiome. Proc Natl Acad Sci U S A. 2011;108(Suppl):4578-85.

[72] Leimbach A, Hacker J, Dobrindt U. Between Pathogenicity and Commensalism [Internet]. Current topics in microbiology and immunology. 2013. 3-32 p. Available from: http://www.ncbi.nlm.nih.gov/pubmed/23340801

[73] Biagi E, Candela M, Franceschi C, Brigidi P. The aging gut microbiota: New perspectives. Ageing Res Rev [Internet]. 2011;10(4):428-9. Available from: http://dx. doi.org/10.1016/j.arr.2011.03.004

[74] Claesson MJ, Cusack S, O'Sullivan O, Greene-Diniz $\mathrm{R}$, de Weerd H, Flannery E, et al. Composition, variability, and temporal stability of the intestinal microbiota of the elderly. Proc Natl Acad Sci [Internet]. 2011;108(Supplement_1):4586-91. Available from: http:// www.pnas.org/cgi/doi/10.1073/pnas.1000097107

[75] Rea MC, O'Sullivan O, Shanahan F, O'Toole PW, Stanton C, Ross RP, et al. Clostridium difficile carriage in elderly subjects and associated changes in the intestinal microbiota. J Clin Microbiol [Internet]. 2012;50(3):86775. Available from: http://www.pubmedcentral.nih.gov/ articlerender.fcgi?artid=3295116\&tool=pmcentrez\&render type $=$ abstract

[76] Mueller S, Saunier K, Hanisch C, Norin E, Alm L, Midtvedt $\mathrm{T}$, et al. Differences in fecal microbiota in different european study populations in relation to age, gender, and country: A cross-sectional study differences in fecal microbiota in different European study populations in relation to age, gender, and country: Enviromental microbiol. 2006;72, No.2(Feb):1027-33.

[77] Li M, Wang B, Zhang M, Rantalainen M, Wang S, Zhou H, et al. Symbiotic gut microbes modulate human metabolic phenotypes. Proc Natl Acad Sci U S A. 2008;105(6):2117-22.

[78] Duncan SH, Lobley GE, Holtrop G, Ince J, Johnstone AM, Louis P, et al. Human colonic microbiota associated with diet, obesity and weight loss. Int J Obes (Lond). 2008;32(11):1720-4.

[79] Andersson AF, Lindberg M, Jakobsson H, Bäckhed F, Nyrén P, Engstrand L. Comparative analysis of human gut 
microbiota by barcoded pyrosequencing. PLoS One [Internet]. 2008;3(7):e2836. Available from: http://www.scopus. com/inward/record.url?eid=2-s2.0-50949131523\&partner ID=tZOtx $3 y 1$

[80] Gill SR, Pop M, Deboy RT, Eckburg PB, Turnbaugh PJ, Samuel BS, et al. Metagenomic Analysis of the Human Distal Gut Microbiome. 2006;312(June): 1355-60.

[81] Eckburg PB, Bik EM, Bernstein CN, Purdom E, Dethlefsen L, Sargent M, et al. Diversity of the human intestinal microbial flora. Science. 2006;308(5728):1635-8.

[82] Shoaie S, Ghaffari P, Kovatcheva-Datchary P, Mardinoglu A, Sen P, Pujos-Guillot E, et al. Quantifying diet-induced metabolic changes of the human gut microbiome. Cell Metab [Internet]. 2015;22(2):320-31. Available from: http: //linkinghub.elsevier.com/retrieve/pii/S1550413115003307

[83] Zwielehner J, Liszt K, Handschur M, Lassl C, Lapin A, Haslberger AG. Combined PCR-DGGE fingerprinting and quantitative-PCR indicates shifts in fecal population sizes and diversity of Bacteroides, bifidobacteria and Clostridium cluster IV in institutionalized elderly. Exp Gerontol [Internet]. Elsevier Inc.; 2009;44(67):440-6. Available from: http://linkinghub.elsevier.com/ retrieve/pii/S0531556509000795

[84] Bartosch S, Fite A, Macfarlane GT, Mcmurdo MET. Characterization of bacterial communities in feces from healthy elderly volunteers and hospitalized elderly patients by using real-time PCR and effects of antibiotic treatment on the fecal microbiota characterization of bacterial communities in feces from. Appl Environ Microbiol. 2004;70(6): 3575-81.

[85] Woodmansey EJ, McMurdo MET, Macfarlane GT, Macfarlane S. Comparison of compositions and metabolic activities of fecal microbiotas in young adults and in antibiotictreated and non-antibiotic-treated elderly subjects. Appl Environ Microbiol [Internet]. 2004;70(10):6113-22. Available from: http://aem.asm.org/content/70/10/6113.full

[86] Hopkins MJ, Sharp R, Macfarlane GT. Age and disease related changes in intestinal bacterial populations assessed by cell culture, 16S rRNA abundance, and community cellular fatty acid profiles. Gut [Internet]. 2001;48(2):198-205. Available from: http://www.pubmed central.nih.gov/articlerender.fcgi?artid=1728209\&tool= pmcentrez\&rendertype $=$ abstract

[87] Hopkins MJ, Macfarlane GT. Changes in predominant bacterial populations in human faeces with age and with Clostridium difficile infection. J Med Microbiol. 2002;51(5):448-54.

[88] Louis P, Hold GL, Flint HJ. The gut microbiota, bacterial metabolites and colorectal cancer. Nat Rev Microbiol [Internet]. Nature Publishing Group; 2014;12(10):66172. Available from: http://www.nature.com/doifinder/ 10.1038/nrmicro3344

[89] Davenport ER, Mizrahi-Man O, Michelini K, Barreiro LB, Ober C, Gilad Y. Seasonal variation in human gut microbiome composition. PLoS One [Internet]. 2014;9(3):e90731. Available from: http://dx.plos. org/10.1371/journal.pone.0090731

[90] Wu GD, Chen J, Hoffmann C, Bittinger K, Chen Y, Sue A, et al. Linking long-term dietary patterns with gut microbial enterotypes. Science (80-). 2012;334(6052): 105-8.
[91] Arumugam M, Raes J, Pelletier E, Paslier D Le, Batto J, Bertalan M, et al. Enterotypes of the human gut microbiome. Nature. 2013;473(7346):174-80.

[92] Cordain L, Miller JB, Eaton SB, Mann N, Holt SHA, Speth JD. Plant-animal subsistence ratios and macronutrient energy estimations in worldwide hunter-gatherer diets. Am J Clin Nutr. 2000;71(3):682-92.

[93] Hawkes K, O'connell JF, Jones NGB. Hinting income patterns among the Hadza: Big game, common goods, forging goals and the evolution of the human diet. Philos Trans Biol Sci. 1991;334:243-51.

[94] Islam KBMS, Fukiya S, Hagio M, Fujii N, Ishizuka S, Ooka $\mathrm{T}$, et al. Bile acid is a host factor that regulates the composition of the cecal microbiota in rats. Gastroenterology [Internet]. 2011;141(5):1773-81. Available from: http://dx.doi.org/10.1053/j.gastro.2011.07.046

[95] Ridlon JM. Bile salt biotransformations by human intestinal bacteria. J Lipid Res [Internet]. 2005;47(2):241-59. Available from: http://www.jlr.org/cgi/doi/10.1194/jlr.R500013JLR200

[96] Yoshimoto S, Loo TM, Atarashi K, Kanda H, Sato $\mathrm{S}$, Oyadomari S, et al. Obesity-induced gut microbial metabolite promotes liver cancer through senescence secretome. Nature [Internet]. Nature Publishing Group; 2013;499(7456):97-101. Available from: http://www.ncbi. nlm.nih.gov/pubmed/23803760

[97] Finegold S, Summanen P, Gerardo SH, Baron E. Clinical importance of Bilophila wadsworthia. Eur J Clin Microbiol Infect Dis [Internet]. 1992;11(11):1058-63. Available from: http://ovidsp.ovid.com/ovidweb.cgi?T=JS\&PAGE= reference $\& D=$ emed2 \&NEWS $=\mathrm{N} \& A N=1993045382$

[98] Baron EJ. Bilophila wadsworthia: A unique Gramnegative anaerobic rod. Anaerobe [Internet]. 1997;3(23):83-6. Available from: http://www.sciencedirect.com/ science/article/pii/S1075996497900755

[99] Devkota S, Wang Y, Musch MW, Leone V, Fehlner-Peach $\mathrm{H}$, Nadimpalli A, et al. Dietary-fat-induced taurocholic acid promotes pathobiont expansion and colitis in Il10 $-/-$ mice. Nature [Internet]. 2012;5-10. Available from: http://www.nature.com/doifinder/10.1038/nature 11225

[100] Flint HJ, Bayer EA, Rincon MT, Lamed R, White BA. Polysaccharide utilization by gut bacteria: Potential for new insights from genomic analysis. Nat Rev Microbiol. 2008;6(2):121-31.

[101] Bergman EN. Energy contributions of volatile fatty acids from the gastrointestinal tract in various species. Physiol Rev. 1990;70(2):567-90.

[102] Tuso PJ, Ismail MH, Ha BP, Bartolotto C. Nutritional update for physicians: Plant-based diets. Perm J [Internet]. 2013;17(2):61-6. Available from: http://www. pubmedcentral.nih.gov/articlerender.fcgi?artid $=3662288 \&$ tool $=$ pmcentrez\&rendertype $=$ abstract

[103] Tremaroli V, Bäckhed F. Functional interactions between the gut microbiota and host metabolism. Nature. 2012; 489(7415):242-9.

[104] Sokol H, Pigneur B, Watterlot L, Lakhdari O, BermúdezHumarán LG, Gratadoux J-J, et al. Faecalibacterium prausnitzii is an anti-inflammatory commensal bacterium identified by gut microbiota analysis of Crohn disease patients. Proc Natl Acad Sci U S A [Internet]. 2008;105(43):16731-6. Available from: http://www. 
pubmedcentral.nih.gov/articlerender.fcgi $?$ artid $=2575488 \&$ tool $=$ pmcentrez\&rendertype $=$ abstract

[105] Martinez-Medina M, Aldeguer X, Gonzalez-Huix F, Acero D, Garcia-Gil JL. Abnormal microbiota composition in the ileocolonic mucosa of Crohn's disease patients as revealed by polymerase chain reaction-denaturing gradient gel electrophoresis. Inflamm Bowel Dis [Internet]. 2006; 12(12):1136-45. Available from: http://content.wkhealth. com/linkback/openurl?sid=WKPTLP:landing page \&an $=00054725-200612000-00007$

[106] Reolon GK, Maurmann N, Werenicz A, Garcia VA, Schröder N, Wood MA, et al. Posttraining systemic administration of the histone deacetylase inhibitor sodium butyrate ameliorates aging-related memory decline in rats. Behav Brain Res [Internet]. Elsevier B.V.; 2011;221(1):329-32. Available from: http://dx.doi.org/ 10.1016/j.bbr.2011.03.033

[107] Govindarajan N, Agis-Balboa RC, Walter J, Sananbenesi F, Fischer A. Sodium butyrate improves memory function in an alzheimer's disease mouse model when administered at an advanced stage of disease progression. J Alzheimer's Dis. 2011;26(1):187-97.

[108] Oudshoorn C, van der Cammen TJM, McMurdo MET, van Leeuwen JPTM, Colin EM. Ageing and vitamin D deficiency: Effects on calcium homeostasis and considerations for vitamin $\mathrm{D}$ supplementation. Br $\mathrm{J}$ Nutr [Internet]. 2009;101(11):1597. Available from: http://www. journals.cambridge.org/abstract_S0007114509338842

[109] Ly NP, Litonjua A, Gold DR, Celedón JC. Gut microbiota, probiotics, and vitamin $\mathrm{D}$ : Interrelated exposures influencing allergy, asthma, and obesity? J Allergy Clin Immunol [Internet]. 2011;127(5):1087-94; quiz 1095-6. Available from: http://www.pubmedcentral. nih.gov/articlerender.fcgi?artid=3085575\&tool=pmcentrez \&rendertype $=$ abstract

[110] Donini L, Savina C, Cannella C. Nutrition in the eldrly: Role of fiber. Arch gerontol geriatr [Internet]. 2009;(Suppl 1):61-9. Available from: http://scholar. google.com/scholar?hl=en\&btnG=Search\&q=intitle:No+ Title\#0

[111] Roberfroid M, Gibson GR, Hoyles L, McCartney AL, Rastall R, Rowland I, et al. Prebiotic effects: Metabolic and health benefits. Br J Nutr. 2010;104(Suppl) (November):S1-63.

[112] Hill C, Guarner F, Reid G, Gibson GR, Merenstein DJ, Pot B, et al. Expert consensus document: The International Scientific Association for Probiotics and Prebiotics consensus statement on the scope and appropriate use of the term probiotic. Nat Rev Gastroenterol Hepatol [Internet]. 2014;11(August 2014):9. Available from: http://www.ncbi.nlm.nih.gov/pubmed/24912386

[113] David S. Oligosaccharides in human milk and bacterial colonization. J Pediatr Gastroenterol Nutr. 2000;30:S8-17.

[114] Harmsen HJ, Wildeboer-Veloo AC, Raangs GC, Wagendorp AA, Klijn N, Bindels JG, et al. Analysis of intestinal flora development in breast-fed and formula-fed infants by using molecular identification and detection methods. J Pediatr Gastroenterol Nutr [Internet]. 2000;30(1):61-7. Available from: http: //www.ncbi.nlm.nih.gov/pubmed/10630441

[115] Macfarlane S, Macfarlane GT, Cummins JH. Review article: Prebiotics in the gastrointestinal tract. Aliment Phar- macol Ther [Internet]. 2006;24(5):701-14. Available from: http://doi.wiley.com/10.1111/j.1365-2036.2006.03042.x

[116] Guarner F. Inulin and oligofructose: Impact on intestinal diseases and disorders. $\mathrm{Br} \mathrm{J}$ Nutr [Internet]. 2005;93(Suppl 1)(S1):S61-5. Available from: http://www. journals.cambridge.org/abstract_S0007114505000826

[117] Khodaei N, Karboune S. Enzymatic generation of galactose-rich oligosaccharides/oligomers from potato rhamnogalacturonan I pectic polysaccharides. Food Chem [Internet]. Elsevier Ltd; 2016;197:406-14. Available from: http://linkinghub.elsevier.com/retrieve/pii/S03088146 15301126

[118] Gómez B, Gullón B, Yáñez R, Schols H, Alonso JL. Prebiotic potential of pectins and pectic oligosaccharides derived from lemon peel wastes and sugar beet pulp: A comparative evaluation. J Funct Foods [Internet]. Elsevier Ltd; 2016;20:108-21. Available from: http:// linkinghub.elsevier.com/retrieve/pii/S1756464615005265

[119] Yang J, Summanen PH, Henning SM, Hsu M, Lam $\mathrm{H}$, Huang J, et al. Xylooligosaccharide supplementation alters gut bacteria in both healthy and prediabetic adults: A pilot study. Front Physiol [Internet]. 2015;6(August):1-11. Available from: http://journal.fron tiersin.org/Article/10.3389/fphys.2015.00216/abstract

[120] Malaguarnera M, Vacante M, Condorelli G, Leggio F, Di Rosa M, Motta M, et al. Probiotics and prebiotics in the management of constipation in the elderly. Acta Medica Mediterr [Internet]. 2013;29(791):791-8. Available from: http://www.actamedicamediterranea.com/medica/2013/ med2013_pag-791-798.pdf

[121] Schiffrin EJ, Thomas DR, Kumar VB, Brown C, Hager C, Vant Hof MA, et al. Systemic inflammatory markers in older persons: The effect of oral nutritional supplementation with prebiotics. J Nutr Heal Aging [Internet]. 2007;11(6):475-9. Available from: http://www.scopus. com/inward/record.url?eid=2-s2.0-37049022798\&partner $\mathrm{ID}=\mathrm{tZOtx} 3 \mathrm{y} 1$

[122] Bouhnik Y, Raskine L, Simoneau G, Vicaut E, Neut C, Flourié B, et al. The capacity of nondigestible carbohydrates to stimulate fecal bifidobacteria in healthy humans: A double-blind, randomized, placebo-controlled, parallelgroup, dose-response relation study. Am J Clin Nutr. 2004;80(6):1658-64

[123] Kleessen B, Sykura B, Zunft HJ, Blaut M. Effects of inulin and lactose on fecal microflora, microbial activity, and bowel habit in elderly constipated persons. Am J Clin Nutr. 1997;65:1397-402.

[124] Fuller R, Gibson GR. Probiotics and prebiotics: Microflora management for improved gut health. Clin Microbiol Infect [Internet]. 1998;4:477-80. Available from: http://doi.wiley.com/10.1111/j.1469-0691.1998.tb00401.x

[125] Fuller R. Probiotics in human medicine. Gut. 1991; 32(4):439-42.

[126] Toward R, Montandon S, Walton G, Gibson GR. Effect of prebiotics on the human gut microbiota of elderly persons. Gut Microbes. 2012;3(November): 57-60.

[127] Ouwehand AC, Bergsma N, Parhiala R, Lahtinen S, Gueimonde M, Finne-Soveri H, et al. Bifidobacterium microbiota and parameters of immune function in elderly subjects. FEMS Immunol Med Microbiol [Internet]. 2008;53(1):18-25. Available from: 14-02-2. 
[128] Klingberg T, Budde B. The survival and persistence in the human gastrointestinal tract of five potential probiotic lactobacilli consumed as freeze-dried cultures or as probiotic sausage. Int $\mathbf{J}$ Food Microbiol [Internet]. 2006;109(1-2):157-9. Available from: http://linking hub.elsevier.com/retrieve/pii/S016816050600064X

[129] Arihara K. Strategies for designing novel functional meat products. Meat Sci [Internet]. 2006;74(1):21929. Available from: http://www.sciencedirect.com/science/ article/pii/S0309174006001446

[130] Ammor MS, Mayo B. Selection criteria for lactic acid bacteria to be used as functional starter cultures in dry sausage production: An update. Meat Sci [Internet]. 2007;76(1):138-46. Available from: http://www. sciencedirect.com/science/article/pii/S0309174006003627

[131] Kleerebezem M, Vaughan EE. Probiotic and gut lactobacilli and bifidobacteria: Molecular approaches to study diversity and activity. Annu Rev Microbiol. 2009;63:269-90.

[132] Terzer M, Maynard ND, Covert MW, Stelling J. Genomescale metabolic networks. Wiley Interdiscip Rev Biol Med. 2009;1(3):285-97.

[133] Maarleveld TR, Khandelwal RA, Olivier BG, Teusink B, Bruggeman FJ. Basic concepts and principles of stoichiometric modeling of metabolic networks. Biotechnol J. 2013;8(9):997-1008.

[134] Orth JD, Thiele I, Palsson B $\varnothing$. What is flux balance analysis? Nat Biotechnol [Internet]. Nature Publishing Group; 2010 Mar [cited 2014 Jul 9];28(3):245-8. Available from: http://www.pubmedcentral.nih.gov/articlerender.fcgi?artid $=3108565 \&$ tool $=$ pmcentrez\&rendertype $=$ abstract
[135] Gianchandani EP, Chavali AK, Papin JA. The application of flux balance analysis in systems biology. WIREs Syst Biol Med. 2009;2(3):372-82.

[136] Karlsson FH, Nookaew I, Petranovic D, Nielsen J. Prospects for systems biology and modeling of the gut microbiome. Trends Biotechnol [Internet]. Elsevier Ltd; 2011;29(6):251-8. Available from: http://dx.doi. org/10.1016/j.tibtech.2011.01.009

[137] Shoaie S, Karlsson F, Mardinoglu A, Nookaew I, Bordel $\mathrm{S}$, Nielsen J. Understanding the interactions between bacteria in the human gut through metabolic modeling. Sci Rep [Internet]. 2013;3:2532. Available from: http://www.pubmedcentral.nih.gov/articlerender.fcgi?artid $=3755282 \&$ tool $=$ pmcentrez\&rendertype $=$ abstract

[138] Emerson D, Agulto L, Liu H, Liu L. Identifying and characterizing bacteria in an era of genomics and proteomics. Bioscience. 2008;58(10):925.

[139] Mardinoglu A, Shoaie S, Bergentall M, Ghaffari P, Zhang $\mathrm{C}$, Larsson $\mathrm{E}$, et al. The gut microbiota modulates host amino acid and glutathione metabolism in mice. Mol Syst Biol [Internet]. 2015;11(10):834-34. Available from: http://msb.embopress.org/cgi/doi/10.15252/msb.20156487

[140] Ji B, Nielsen J. From next-generation sequencing to systematic modeling of the gut microbiome. Front Genet [Internet]. 2015;6(June):219. Available from: http://journal. frontiersin.org/Article/10.3389/fgene.2015.00219/abstract

[141] Zeevi D, Korem T, Zmora N, Israeli D, Rothschild D, Weinberger A, et al. Personalized nutrition by prediction of glycemic responses. Cell. 2015;163(5):1079-95. 